\title{
Microvascular dysfunction in the course of metabolic syndrome induced by high-fat diet
}

\author{
Cristiane Aoquil, Stefan Chmielewski ${ }^{1,2}$, Elias Scherer ${ }^{3}$, Ruth Eißler ${ }^{1}$, Daniel Sollinger ${ }^{1}$, Irina Heid ${ }^{4}$, Rickmer Braren ${ }^{4}$, \\ Christoph Schmaderer ${ }^{1}$, Remco TA Megens ${ }^{5,6}$, Christian Weber ${ }^{5,6,7}$, Uwe Heemann', Matthias Tschöp ${ }^{8}$ \\ and Marcus Baumann ${ }^{1 *}$
}

\begin{abstract}
Background: Metabolic syndrome (MetS) is associated with increased risk of cardiovascular disease (CVD). One important feature underlying the pathophysiology of many types of CVD is microvascular dysfunction. Although components of MetS are themselves CVD risk factors, the risk is increased when the syndrome is considered as one entity. We aimed to characterize microvascular function and some of its influencing factors in the course of MetS development.

Methods: Development of MetS in C57BL/6 mice on a high-fat diet (HFD, 51\% of energy from fat) was studied. The initial phase of MetS (I-MetS) was defined as the first 2 weeks of HFD feeding, with the fully developed phase occurring after 8 weeks of HFD. We characterized these phases by assessing changes in adiposity, blood pressure, and microvascular function. All data are presented as mean \pm standard error (SEM). Differences between cumulative dose-response curves of myograph experiments were calculated using non-linear regression analysis. In other experiments, comparisons between two groups were made with Student's t-test. Comparisons between more than two groups were made using one-way ANOVA with Tukey post-hoc test. A probability value $<0.05$ was considered statistically significant.

Results: I-MetS mice presented with weight gain, blood pressure elevation, and microvascular dysfunction characterized by augmented vasoconstriction. This finding, contrary to those in mice with fully developed MetS, was not associated with endothelial dysfunction, insulin resistance, or systemic inflammation. In the initial phase, perivascular adipose tissue showed no sign of inflammation and had no influence on the pattern of vasoconstriction. These findings suggest that the onset of hypertension in MetS is strongly influenced by vascular smooth muscle cell dysfunction and independent of important factors known to influence microvascular function and consequently blood pressure levels.

Conclusion: We identified in I-MetS the occurrence of isolated augmented vasoconstriction along with blood pressure elevation, but not the presence of classical MetS components known to influence microvascular function. These findings increase our understanding of the pathophysiology of CVD risk associated with MetS.
\end{abstract}

Keywords: High-fat diet, Metabolic syndrome, Hypertension, Microvascular dysfunction, Vasoconstriction

\section{Background}

Cardiovascular disease (CVD) is the leading cause of death worldwide. Although highly influenced by nonmodifiable risk factors such as age, family history, and gender, CVD is largely caused by risk factors that can be treated or at least controlled [1]. Most of the modifiable risk factors are disorders typically associated with obesity

\footnotetext{
* Correspondence: Marcus.baumann@|rz.tum.de

'Department of Nephrology, Klinikum rechts der Isar der Technischen Universität München, Ismaninger St. 22, Munich 81675, Germany Full list of author information is available at the end of the article
}

that commonly cluster together, such as abdominal obesity, insulin resistance, dyslipidemia, and hypertension. These disorders are components of the so-called metabolic syndrome (MetS) [2]. Different clinical criteria have been proposed as being diagnostic of MetS. The National Cholesterol Education Program Adult Treatment Panel III definition is one of those most widely used [3], and defines MetS as the occurrence of three or more of the following five criteria: waist circumference over $102 \mathrm{~cm}$ (men) or $88 \mathrm{~cm}$ (women), blood pressure $\geq$ $130 / 85 \mathrm{mmHg}$, fasting triglyceride level $\geq 150 \mathrm{mg} / \mathrm{dl}$, fasting high-density lipoprotein cholesterol level less 
than $40 \mathrm{mg} / \mathrm{dl}$ (men) or $50 \mathrm{mg} / \mathrm{dl}$ (women), and fasting glucose level $\geq 100 \mathrm{mg} / \mathrm{dl}$. The association between MetS and a high risk of developing CVD is extensively reported in the literature [4-6].

Regarding the underlying processes of CVD development, key components appear to be structural and functional alterations of the microvasculature, laying the foundations for target organ damage [7]. The microvasculature consists of the smallest arteries, the arterioles, capillaries, and venules [8], therefore including the so-called resistance arteries, which consist mainly of arteries $<400 \mu \mathrm{m}$ and arterioles $<100 \mu \mathrm{m}$ in lumen diameter [9]. Dysfunction of the microvasculature has been associated with features of MetS and has been reported in different ways [10-12]. MetS components, such as insulin resistance, dyslipidemia, arterial hypertension, and abdominal obesity, can independently influence microvascular function [13-16]. In obesity, pathological adipose tissue is associated with microvascular dysfunction [16,17], and, more specifically, perivascular adipose tissue (PVAT) is now accepted to be an important modulator of vascular function $[16,18,19]$. Vascular anticontractile properties of PVAT were described to be mediated through the hormone adiponectin [16]. In Zucker lean rats, adiponectin provoked vasodilation of mesenteric arteries, dependent on nitric oxide (NO). In their diabetic littermates, the Zucker Diabetic Fatty rats, the vasodilation caused by adiponectin was diminished and associated with endothelial dysfunction [20]. Controversy surrounds the theory that restoring adiponectin levels is associated with improvement in endothelial function [21,22]. More recently, contractile properties of adiponectin were also identified, related to alterations in the PVAT proteome in obesity [23]. Thus, the precise characteristics of microvascular dysfunction observed in MetS remain unclear owing to the simultaneous occurrence of different disorders and their complex interaction.

In rodents, hormonal, metabolic, and cardiovascular disorders induced by hypercaloric diets are widely reported. Oliveira et al. reported that hyperglycemia, systolic blood pressure disorders, and cardiac remodeling were induced by a hypercaloric diet for 20 weeks in Wistar-Kyoto rats [24]. Sarkozy et al. reported features of MetS in Zucker Diabetic Fatty rats associated with altered cardiac expression of genes related to metabolism, signal transduction, stress response, and receptors [25]. In this study, we used the C57BL/6 mouse, which is a model widely used to study diet-induced obesity as it develops features observed in human MetS [26]. We assessed microvascular function through the mesenteric arterial arcade [27], which, in rodents, contributes substantially to regulation of peripheral resistance [28] and blood pressure [29].

We aimed to characterize features of microvascular function during MetS development in a mouse model, particularly during the initial phase when confounding factors known to influence microvascular function are not completely established. In addition, we investigated the influence of endothelium and PVAT, two important mediators of an unfavorable relationship between MetS and microvascular function.

\section{Methods}

\section{Animals and diets}

Male wild-type C57BL/6 J (WT) mice were housed in temperature-controlled cages $\left(20^{\circ} \mathrm{C}\right.$ to $\left.22^{\circ} \mathrm{C}\right)$ and maintained on a 12/12-hour light/dark cycle. At the age of 12 weeks mice were randomly assigned to either a control diet (9\% of calories from fat, 33\% from protein, and $58 \%$ from carbohydrates) or to a high-fat diet (HFD, 51\% from fat, $23 \%$ from protein, and $26 \%$ from carbohydrates). Both diets were purchased from Ssniff (Soest, Germany). We defined the group who received HFD for 8 weeks as the metabolic syndrome group (MetS) and HFD for 2 weeks as the initial metabolic syndrome group (I-MetS). WT mice were obtained from Charles River Laboratories (Sulzfeld, Germany). During isoflurane anesthesia mice were fixed on a heat-controlled plate and an intra-arterial pressure transducer was inserted in the left carotid artery under sterile conditions. Intra-arterial blood pressure was measured continuously for 15 minutes (Blood Pressure Monitor BP1, World Precision Instruments, Sarasota, FL, USA). Thereafter, animals were sacrificed and the entire intestine, including vascular arcades, was immediately excised and stored in cold 3-( $N$-morpholino)propanesulfonic acid (MOPS) buffer for wire myograph studies. Changes in whole body weight and epididymal fat pad weight were assessed as parameters of visceral fat status. Serum was collected in serum separator tubes (Sarstedt, Nümbrecht, Germany) and stored at $-80^{\circ} \mathrm{C}$ for subsequent experiments. All animals received humane care and all animal protocols were fully compliant with the principles of the Guide for the Care and Use of Laboratory Animals from the National Institutes of Health and German Law on the Protection of Animals was followed. The protocol was approved by the government of Bayern's Animal Care Committee, Regierung von Oberbayern, Munich, Germany (Protocol number: AZ 55.2-1-54-253119-09). The mice were observed daily for any signs of distress and weighed weekly to monitor health. Blood pressure measurement in the carotid artery was performed under isoflurane anesthesia, and termination was performed with cervical dislocation. All efforts were made to minimize suffering.

\section{Magnetic resonance imaging}

Whole body magnetic resonance imaging (MRI) was performed on mice anesthetized with intraperitoneal 
pentobarbital and placed in the prone position on a 47 $\mathrm{mm}$ microscopy surface coil inside the clinical $1.5 \mathrm{~T}$ MRI System (Achieva 1.5 T, Philips Medical Systems, Best, The Netherlands). An axial, multi-slice, turbo spin echo sequence [resolution $0.25 \times 0.25 \times 0.35 \mathrm{~mm}^{3}, 140$ slices, echo time $(\mathrm{TE})=100 \mathrm{~ms}$, repetition time $(\mathrm{TR})=$ $1000 \mathrm{~ms}$ was applied to suppress signal from tissue other than fat. The whole body images were reconstructed using an OsiriX DICOM viewer.

\section{Biochemical measurements}

Serum fasting total cholesterol, triglycerides, and glucose levels were measured by enzymatic methods (Roche Diagnostics). Fasting insulin was measured by enzymelinked immunosorbent assay (ELISA) kit (Shibayagi, Shibukawa, Japan). The insulin resistance index [homeostasis model assessment (HOMA-IR)] was calculated using fasting insulin and glucose values: [insulin (picomoles per liter $\times$ glucose (millimoles per liter)]/22.5 [30,31]. Serum tumor necrosis factor- $\alpha$ (TNF- $\alpha$ ) and interleukin-6 (IL-6) were measured with murine ELISA kits (Peprotech, Hamburg, Germany). Dissected mesenteric PVAT was snap-frozen and protein extracts were used for Rhoassociated kinase activity measurement by an enzyme immunoassay (Cell Biolabs, San Diego, CA, USA). Measurements were performed according to the manufacturer's protocol using $10 \mu \mathrm{g}$ of protein lysate. Values are reported as percentage of activity related to controls.

\section{Histology}

Epididymal fat pads and mesenteric vascular beds with PVAT were fixed in paraformaldehyde, embedded in paraffin, and subsequently stained with hematoxylineosin. For each mouse, the area of 50 randomly chosen adipocytes was measured in five representative sections using Image J software (National Institutes of Health, USA) at $10 \times$ magnification. Mean values given in pixels were compared. Analysis of infiltrating leukocytes in mesenteric PVAT was performed by immunohistochemical staining for CD45 (Becton \& Dickenson, Franklin Lakes, NJ, USA). The total number of CD45-positive cells was counted in ten randomly chosen arteries per whole mesenteric vascular bed per mouse and the average calculated.

\section{Two-photon microscopy}

Small mesenteric arteries and correspondent PVAT were visualized using a Leica SP5 II MP two-photon laser scanning microscope coupled with a water dipping $20 \times$ NA 1.00 objective and a pre-chirped Ti:Sa laser (Spectra Physics, Springfield, OH, USA) tuned to $840 \mathrm{~nm}$ [32]. Four hybrid detectors (HyD) were spectrally tuned for optimal detection efficiency and low bleed through of signal: second harmonic generation of collagen (HyD1:
400-425 nm), autofluorescence of adipocytes and GR1/ eFluor450 (HyD2: 445-500 nm), autofluorescence of adipocytes/elastin, and CD115/Alexa488 (HyD3: 515555 nm) CD45/nanocrystal-605 nm (HyD4: 590$625 \mathrm{~nm}$ ). Additional image processing was performed using Leica LAF AF 3.0 and ImagePro. Quantification of inflammatory cells was performed by detecting the number of cells positive for CD45/CD115 (monocyte and macrophage marker) and for CD45/Gr-1 (marker for neutrophil in peripheral organs) in each arterial segment recorded in $3 \mathrm{D}$ datasets $(n=3$ arterial segments per mouse, $n=4$ mice per group). All antibodies were from eBioscience (San Diego, CA, USA). We counted the number of inflammatory cells using 3D datasets from the PVAT of the small mesenteric arteries (up to a distance of three times the average adipocyte diameter from the small artery). The adipocyte volume was determined by measuring maximal diameter in the corresponding arterial segment, assuming a spherical cell shape. The total number of positive cells is presented as inflammatory cells per adipocyte.

\section{RNA isolation and real-time polymerase chain reaction} Dissected mesenteric PVAT was snap-frozen in liquid nitrogen and stored at $-80^{\circ} \mathrm{C}$. Then, $80 \mathrm{mg}$ of tissue was used for RNA isolation using RNeasy Lipid Tissue mini kit (Qiagen, Hilden, Germany) according to the manufacturer's protocol. Quality of RNA was assessed using Bioanalyzer (BioRad, Hercules, CA, USA). Complementary DNA was synthesized using iScript cDNA Synthesis Kit (BioRad), according to the manufacturer's protocol. Quantitative reverse transcriptase polymerase chain reaction (PCR) was performed using SYBR Green I (MyiQ ICycler, Bio-Rad). Gene expression of TNF- $\alpha$, IL-6, monocyte chemotactic protein-1 (MCP-1), Toll-like receptor 4 (TLR4), RhoA, Rho-kinase 1 (ROCK1), and Rho-kinase 2 (ROCK2) were investigated. cDNA primers (sense and anti-sense) were as follows: glyceraldehyde 3phosphate dehydrogenase (GAPDH) (TCGGTGTGAAC GGATTTGGC and TTTGGCTCCACCCTTCAAGTG), TNF- $\alpha$ (CCAAAGGGATGAGAAGTTCC and GGCAGAGAGGAGGTTGACTTT), IL-6 (CTGGGAAATCG TGGAAATGAG and ACTCTGGCTTTGTCTTTCT TG), MCP-1 (GCTGTAGTTTTTGTCACCAAG and GATTTACGGGTCAACTTCACA), TLR4 (ATTCCCTCAGCACTCTTGATT and AGTTGCCGTTTCTTGTT CTTC), RhoA (CTCTCTTATCCAGACACCGAT and CAAAAACCTCTCTCACTCCATC), ROCK 1 (AAGG CGGTGATGGCTATTATG and TCCTCTACACCATT TCTGCCC), and ROCK 2 (ATGTGATTGGTGGTCTGTAGGT and AGCTGCCGTCTCTCTTATGTTA). Quantification was made using the $\mathrm{ddCt}$ algorithm, including normalization of each sample to GAPDH [33]. The results are expressed as the multiple of the control value from three independent experiments. 


\section{Western blot}

Total adiponectin and adiponectin multimers were determined by Western blotting in serum. Sodium dodecyl sulfate polyacrylamide gel electrophoresis (SDS-PAGE) was performed. In brief, serum proteins were separated by $10 \%$ SDS-PAGE under non-reducing and non-heating conditions, and transferred to nitrocellulose membranes. Membranes were blocked with Tris-buffered saline-Tween 20 containing $5 \%$ skim milk and incubated with a goat antihuman adiponectin polyclonal antibody (1:500). After washing, membranes were incubated with horseradish peroxidase conjugated-donkey anti-goat antibody (1:4000). Bands were visualized by using lumi-light Western blotting substrate, and the image was acquired with a Kodak IS440CF Imaging Station. Densitometry analysis was performed with Adobe Photoshop software. Relative distributions of adiponectin multimers were calculated by dividing band density by total density.

\section{Wire myograph and microvascular studies}

First- to second-order branches from the superior mesenteric artery $(270-330 \mu \mathrm{m})$ were cleaned of PVAT, cut into 2-mm-long rings, and mounted in a 4-channel wire myograph (Model 620 M, Danish Myo Technology, Aarhus, Denmark). Each vessel segment was mounted on two tungsten wires ( $40 \mu \mathrm{m}$ diameter) in the organ chamber filled with MOPS buffer. MOPS buffer consisted of (in $\mathrm{mM}): \mathrm{NaCl}$ 145, $\mathrm{KCl} 4.7, \mathrm{CaCl}_{2}$ 3.0, $\mathrm{MgSO}_{4}$ 1.17, $\mathrm{NaH}_{2} \mathrm{PO}_{4}$ 1.2, pyruvate 2.0, EDTA 0.02, MOPS 3.0, and glucose 5.0. Vessels were pre-stretched to a tension representing a blood pressure of 13.3 kilopascal and equilibrated at this tension for 30 minutes at $37^{\circ} \mathrm{C}$ [34]. Subsequently, the organ bath solution was changed for a fresh pre-heated MOPS buffer and vascular functions were analyzed. During the experiments, the diameter of the vessels was kept constant, so the vessels could be examined under isometric conditions. For testing viability, vessels were subjected to norepinephrine-induced constriction followed by acetylcholine. Vessels with endotheliumdependent relaxation in the presence of acetylcholine that was greater than $70 \%$ of the maximal norepinephrine vasoconstriction were considered to have an intact endothelium. After washing out with MOPS buffer and resting for $20 \mathrm{~min}$, norepinephrine $\left(10^{-9}\right.$ to $\left.10^{-5} \mathrm{M}\right)$ and acetylcholine $\left(10^{-10}\right.$ to $\left.10^{-5} \mathrm{M}\right)$ dose-response curves were constructed. Relaxation of preconstricted (high potassium chloride, $125 \mathrm{mM}$ ) vessels in response to an external NO donor (sodium nitroprusside, $10^{-10}$ to $10^{-5} \mathrm{M}$ ) was measured. Response was expressed as a percentage of potassium-induced constriction.

In the set of experiments designed to study the influence of PVAT on vascular response, one segment of a small mesenteric artery was cleaned of PVAT while the adjacent segment was left uncleaned. Arteries were first constricted with norepinephrine $\left(10^{-5} \mathrm{M}\right)$ to obtain the baseline response. After washing and resting for $20 \mathrm{~min}$, norepinephrine dose-response curves were constructed, where the response was expressed as a percentage of the baseline norepinephrine-induced contraction.

\section{Statistical analysis}

All data are presented as mean \pm standard error of the mean (SEM). In cumulative dose-response curves of myograph experiments, the logEC50 value for tissue from each mouse (two to four arteries per mouse) was calculated. Differences between logEC50 values were calculated using non-linear regression analysis. In other experiments, comparisons between two groups were made with Student's $t$-test. For comparisons between more than two groups, one-way ANOVA with Tukey post-hoc test was used. A probability value of $<0.05$ was considered statistically significant (GraphPad Prism ${ }^{\bullet} 5.0$ ).

\section{Results}

\section{A mouse model to investigate the initial phase of} metabolic syndrome

A high-fat diet was used to induce features of MetS in WT mice. As expected, WT mice fed a HFD for 8 weeks (MetS group) gained a significant amount of weight, and showed a marked increase in visceral fat tissue (mesenteric PVAT and epididymal fat pads) and hypertrophy of adipocytes. Mean arterial blood pressure was significantly elevated (control: $70.5 \pm 2.1 \mathrm{mmHg}$ vs. MetS: $82.7 \pm$ $1.6 \mathrm{mmHg}, P<0.01$ ) (Figure 1A). MetS group mice also presented with insulin resistance and systemic inflammation, as measured by increases in HOMA-IR and serum TNF- $\alpha$ level, respectively (Figure 1C).

Compared with controls, mice fed a HFD for 2 weeks (I-MetS group) also had significantly heavier epididymal fat pads and increased mesenteric PVAT, accompanied by adipocyte hypertrophy (Figure 1B). However, disorders associated with MetS, such as insulin resistance and systemic inflammation, were not present (Figure 1C). Mean arterial blood pressure was significantly elevated in I-MetS group mice, as was observed in the MetS group (control: $72 \pm 1.3 \mathrm{mmHg}$ vs. I-MetS: $85 \pm$ $1.0 \mathrm{mmHg}, P<0.001$ ) (Figure $1 \mathrm{~B}$ ).

\section{The initial phase of MetS presents with augmented} vasoconstriction, independent of endothelium and PVAT In MetS mice, small mesenteric arteries had an augmented response to the vasoconstrictor norepinephrine, demonstrated by measurement of sensitivity (control: logEC50 -6.170 vs. MetS: $\operatorname{logEC50}-6.664, P<0.001)$. In MetS mice, relaxation in response to acetylcholine was significantly lower compared with control, and that to sodium nitroprusside was significantly augmented (Figure 2A). IMetS group mice also had increased sensitivity to 


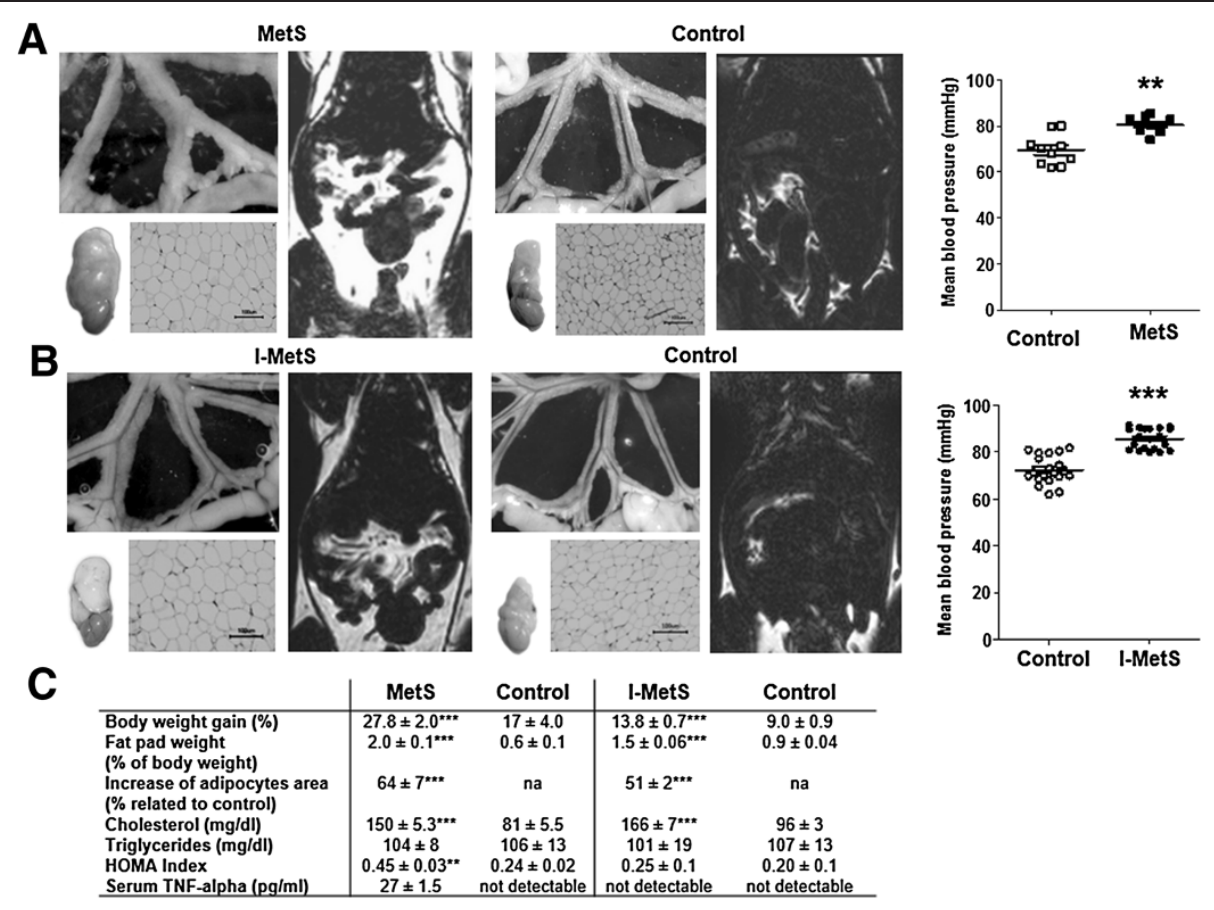

Figure 1 Features of metabolic syndrome in WT mice. A, After a HFD for 8 weeks (Metabolic Syndrome = MetS) and B, 2 weeks (Initial Metabolic Syndrome $=1-M e t S)$, there was increase in visceral fat tissue seen in mesenteric PVAT, epididymal fat pads, adipocyte hypertrophy and hyperintense areas displaying fat depots in magnetic resonance imaging. Elevation of blood pressure was seen in MetS and I-MetS groups. C, Comparative table of weight and metabolic parameters $(n=10-15$ mice/group). Data are presented as mean $\pm S E M, n=10-20$ mice/group, $* * 00.01, * * *<0.001$, na $=$ not applicable.

\section{A}

\section{ㅁ. Control}
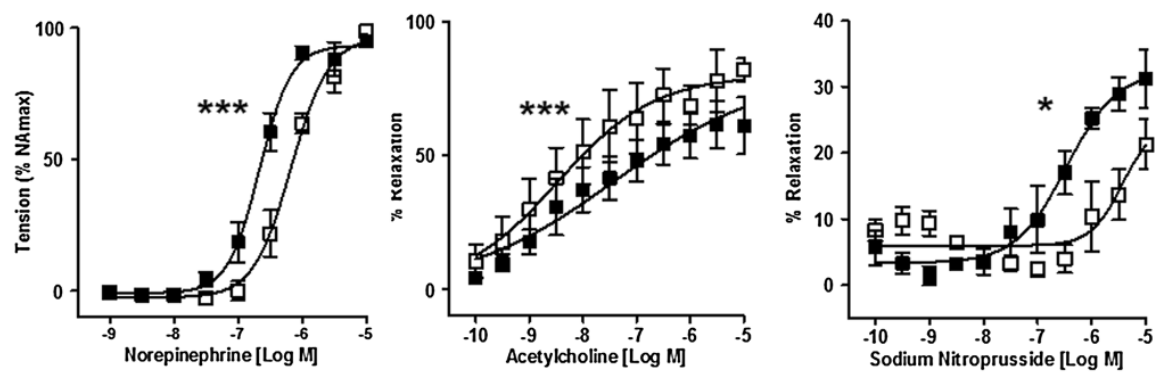

B
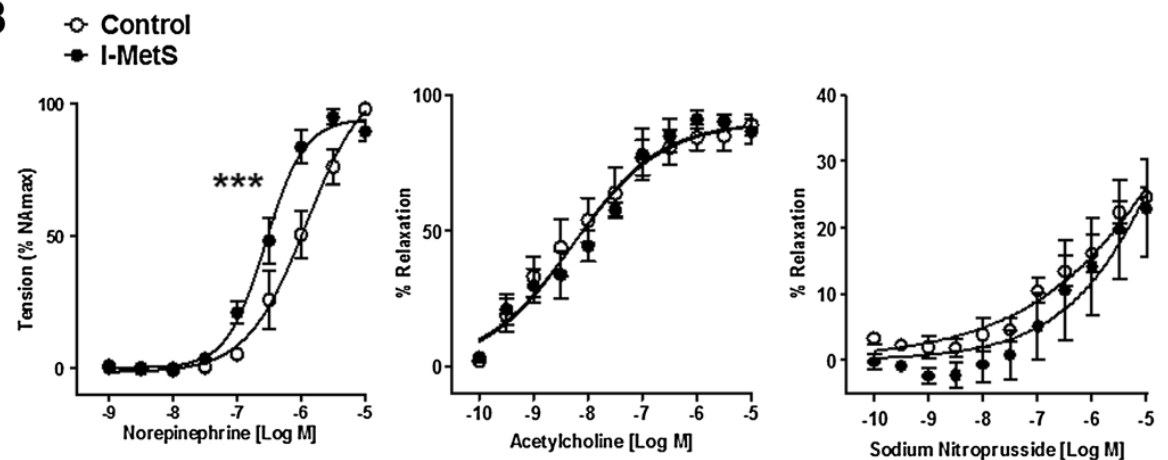

Figure 2 Microvascular function in MetS and I-MetS mice. A, Norepinephrine-induced vasoconstriction was significantly increased, acetylcholineinduced relaxation was reduced and responses to sodium nitroprusside were increased in MetS mice. B, Similarly to MetS, the I-MetS group also presented increased vasoconstriction but without differences in relaxation responses. Data are presented as mean $\pm S E M, n=10$ mice/group, ${ }^{*} P<0.05$, ${ }^{* * *} P<0.001$. 
norepinephrine (control: logEC50 -5.921 vs. I-MetS: $\operatorname{logEC50}-6.556, P<0.001$ ), but relaxation responses to acetylcholine and sodium nitroprusside were the same as seen in control mice (Figure 2B). Mechanical removal of the endothelium (Figure 3A) did not affect the pattern of vasoconstriction responses in arteries from MetS and IMetS mice, suggesting that these vascular findings are at least partially independent of endothelium integrity (Figure 3B).

Next, we investigated mesenteric PVAT. Infiltration by inflammatory cells was first investigated by immunohistochemistry. The number of cells positive for the panleukocyte marker CD45 was increased only in MetS mice and not in the I-MetS group (Figure 4A). Twophoton microscopic imaging of small mesenteric arteries surrounded by PVAT showed that the number of cells positive for CD45/CD115 (monocytes and macrophages) and CD45/Gr-1 (neutrophils) tended to increase $(P=$ $0.06)$ in the PVAT from just MetS mice (Figure 4B). Gene expression of inflammatory markers, such as MCP-1 and TLR4, were significantly increased in the PVAT from just MetS mice (Figure 4C).

To investigate the influence of PVAT in vasoconstriction responses we examined arteries with and without this tissue. In control mice, PVAT has an anticontractile effect (Figure 5A). The data obtained strongly suggest that, in I-MetS mice, PVAT keeps its anticontractile properties (Figure 5B), whereas the MetS group has lost this characteristic (Figure 5C). Among the reported PVAT-derived effectors that can influence vascular contractility are adiponectin levels and activation of the RhoA/Rho-kinase pathway. Adiponectin is present in the circulation as three distinct oligomeric complexes [35] and it has been described as having a key role in modulating vascular function [16]. However, in I-MetS mice, levels of adiponectin, and in particular of highmolecular weight (HMW) adiponectin, were unchanged compared with controls. In contrast, MetS mice had significantly reduced HMW adiponectin (Figure 5D). In the PVAT from MetS mice (Figure 6A), gene expression of the small GTPase RhoA and of two of its downstream effectors, ROCK1 and ROCK2, was increased. In MetS mice Rho-kinase activity was increased, but this was not observed in the PVAT from I-MetS mice (Figure 6B). To summarize, in contrast with MetS mice, I-MetS mice exhibited augmented vasoconstriction that was independent of PVAT and some of its described vasoactive effectors.

\section{Discussion}

This study was designed to investigate microvascular function during the development of MetS induced by HFD. We showed that microvascular dysfunction in the form of augmented vasoconstriction was already present in the initial phase of MetS, as was blood pressure elevation. These early vascular alterations developed in the

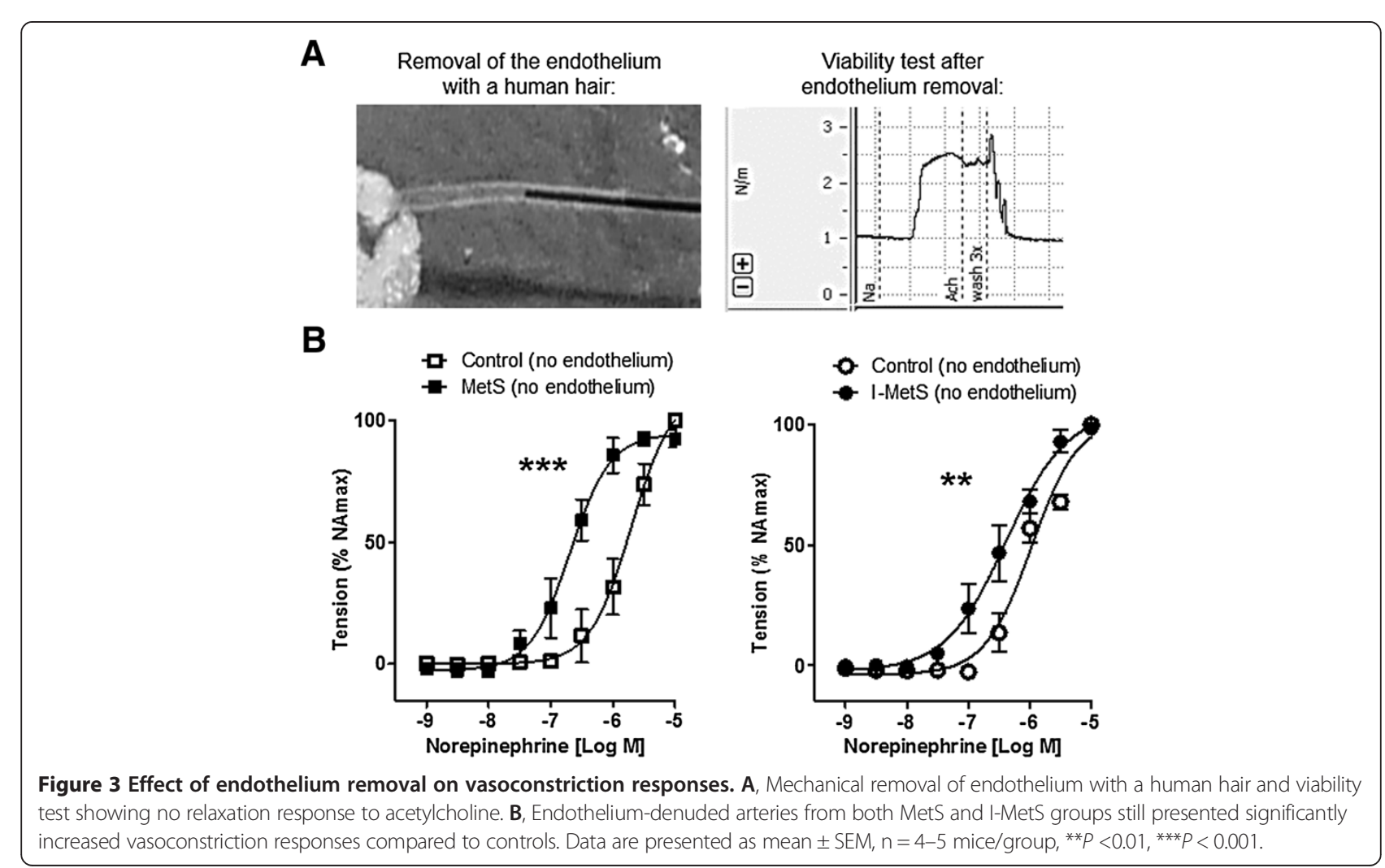


A
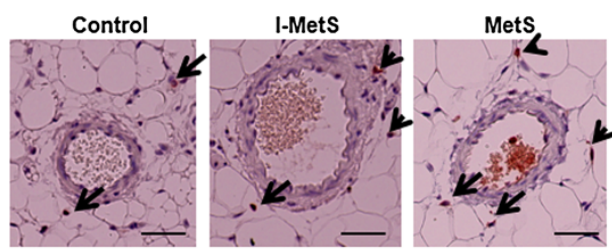

B
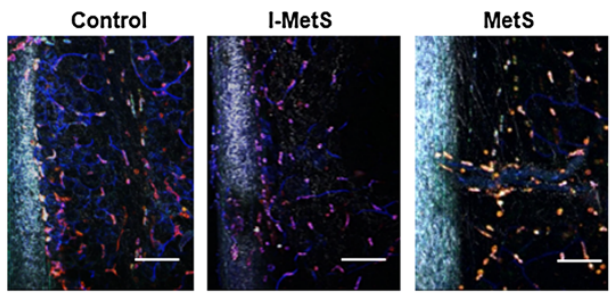

C
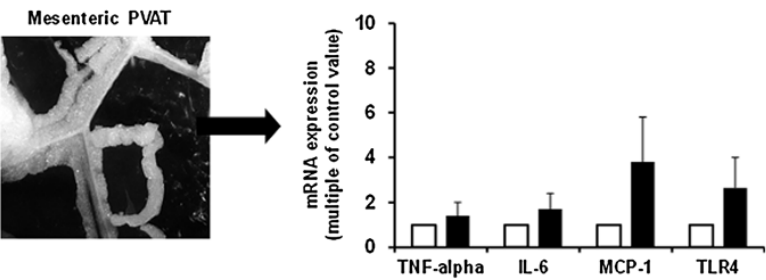

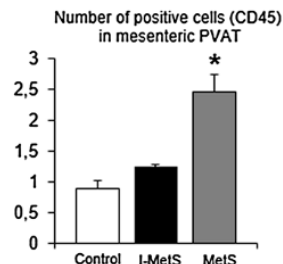

Positive cells per adipocyte in mesenteric PVAT

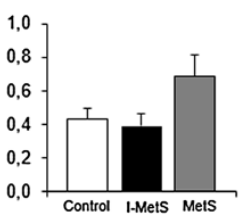

Figure 4 Inflammatory cell infiltration in mesenteric perivascular adipose tissue (PVAT). A, Representative images of CD45 immunohistochemical staining of a small mesenteric artery and surrounding PVAT. The number of CD45-positive cells was not different between I-MetS mice and controls, but it was increased in MetS mice (data are presented as mean $\pm \mathrm{SEM}, \mathrm{n}=6$ mice/group, ${ }^{*} P<0.05$, scale bars $=50 \mu \mathrm{m}$ ). B, Representative images of two-photon microscopy of a small mesenteric artery on the left, with the surrounding PVAT stained for CD45/CD115 and CD45/Gr-1. I-MetS mice did not present with increased number of positive cells. In MetS mice there was a trend toward more positive cells $(P=0.06, \mathrm{scale}$ bars $=100 \mu \mathrm{m})$. The column graph represents the number of positive cells per arterial segment examined (data are presented as mean \pm SEM, 3 segments/mouse, $n=4$ mice/group). C, In contrast with MetS mice, I-MetS mice did not present increased expression of inflammatory genes in mesenteric PVAT. Results represent three independent experiments, $\mathrm{n}=3-4 \mathrm{mice} / \mathrm{group}$, data are presented as mean $\pm \mathrm{SEM},{ }^{*} P<0.05,{ }^{* *} P<0.01$.

absence of important factors known to influence microvascular function, such as insulin resistance, systemic inflammation, and endothelial and PVAT dysfunction, which were only observed in a later phase of MetS.

\section{Microvascular dysfunction was present already in the initial phase of metabolic syndrome}

Prolonged HFD in C57BL/6 mice is an established model of diet-induced MetS [26]. In our study I-MetS mice presented with mild weight gain, a prominent visceral fat increase, hypercholesterolemia, and blood pressure elevation; however, systemic inflammation and insulin resistance were not observed. After 8 weeks of HFD, mice presented with features similar to those found in human MetS, such as weight gain with a marked increase in visceral fat, hypercholesterolemia, and blood pressure elevation. In addition to these classical components, MetS mice presented with insulin resistance and systemic inflammation indicated by elevated TNF- $\alpha$ and reduced adiponectin levels. These factors are part of the additional metabolic criteria suggested for research by the International Diabetes Federation, aiming at further modification of the MetS definition [36].
Concerning the microvasculature, MetS mice presented with augmented vasoconstriction responses to norepinephrine, while the relaxation responses to acetylcholine and sodium nitroprusside were reduced and augmented, respectively, suggesting endothelial dysfunction. Similarly, augmented vasoconstriction in the presence of norepinephrine was present in I-MetS mice. However, contrary to MetS mice, relaxation induced by acetylcholine and sodium nitroprusside was preserved in I-MetS mice, suggesting the integrity of endothelial function. Obesity is reported to be associated with impaired NO bioavailability with a compensatory increase in the activity of soluble guanylyl cyclase [37], the major cellular receptor for NO. The augmented relaxation responses to sodium nitroprusside, an external source of NO, suggest impaired NO bioavailability and, together with decreased relaxation responses to acetylcholine, strongly suggest diminished endothelial function. Therefore, augmented vasoconstriction in the absence of endothelial dysfunction as observed in I-MetS mice strengthens the evidence of a role for vascular smooth muscle cells. It is known that endothelial function can be influenced by the presence of insulin resistance [14], systemic 
A
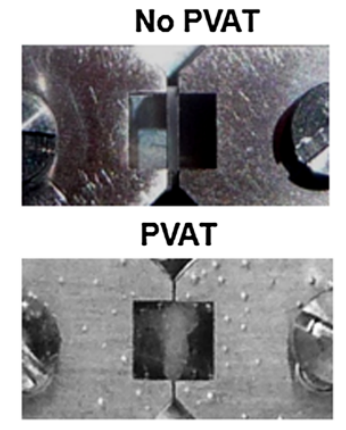

B

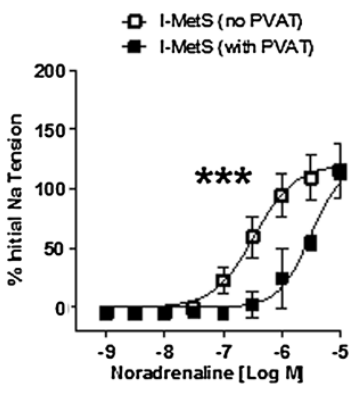

D

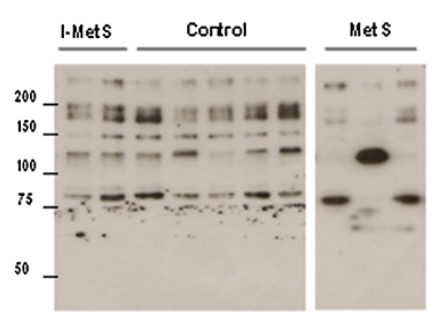

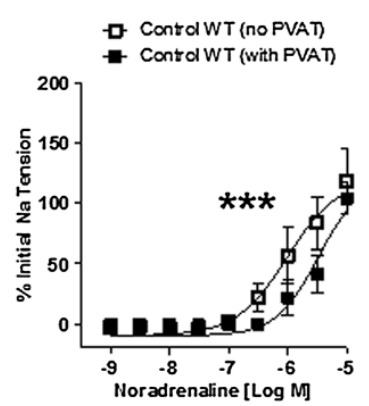

C
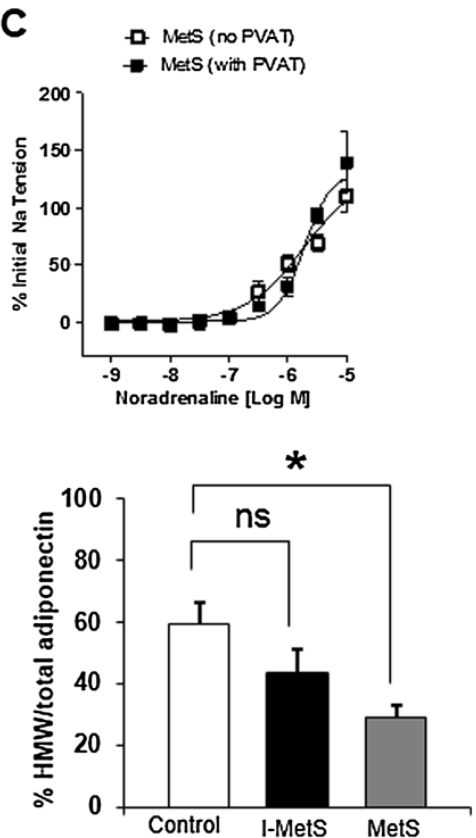

Figure 5 Role of PVAT in vascular responses and adiponectin measurement. A, Arteries examined in the myograph without and with PVAT, control mice. B, I-MetS mice showed PVAT with anticontractile properties similar to control mice. C, MetS mice did not present with this effect anymore (Data presented as mean $\pm \mathrm{SEM}, \mathrm{n}=4$ mice/group, $\left.{ }^{* * *} P<0.001\right)$. D, Lower levels of high-molecular weight (HMW) adiponectin in relation to total adiponectin in serum were seen only in MetS mice (Data presented as mean $\pm S E M, n=5$ mice/group, ${ }^{*} P<0.05$, ns $=$ not significant).

inflammation [38], and dysfunctional adipose tissue [16,39]; therefore, association of these factors in MetS mice was expected. In contrast to these findings in MetS mice, the augmented vasoconstriction in I-MetS mice was independent of endothelial dysfunction, insulin resistance, and systemic inflammation.

Human MetS has been associated with an increased risk of CVD such as myocardial infarction, stroke [40], and coronary microvascular dysfunction linked to a microvascular form of angina pectoris [11]. Microvascular dysfunction is reported to be associated with poor cardiovascular outcomes [41,42], including left ventricular remodeling [43]. Thus, identification of specific MetS components that are associated with microvascular dysfunction might help illuminate the pathophysiology of CVD in MetS. The communitybased Bogalusa Heart Study evaluated normotensive, prehypertensive, and hypertensive adults. The study showed that the early natural history of hypertension was characterized by excess adiposity and blood pressure beginning in childhood and unfavourable changes in risk variables of MetS occuring through young adulthood. Importantly, our study showed that, as in MetS mice, I-MetS mice presented with blood pressure elevation plus augmented vasoconstriction, suggesting that there is a close relationship between these features because the microcirculation actively regulates blood pressure control [8]. Therefore, augmented vasoconstriction could underlie the onset of hypertension in MetS.

\section{Dysfunction of adipose tissue was absent in the initial phase of metabolic syndrome}

The vasoactive properties of PVAT are now recognized as being protective in healthy conditions [16]. However, in the setting of obesity, for example, inflammation in adipose tissue, such as that caused by macrophage 


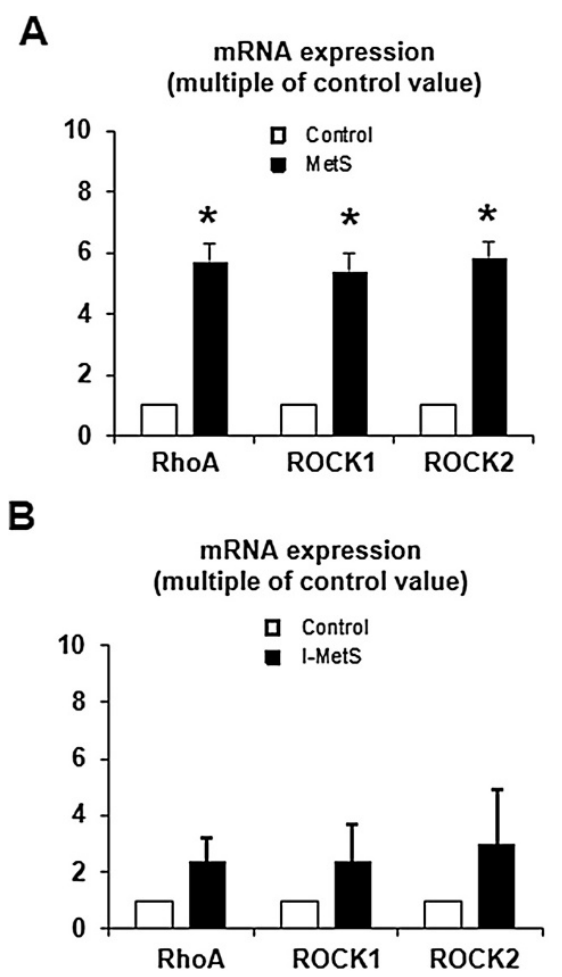

\section{Rho-associated kinase activity (\% related to controls)}

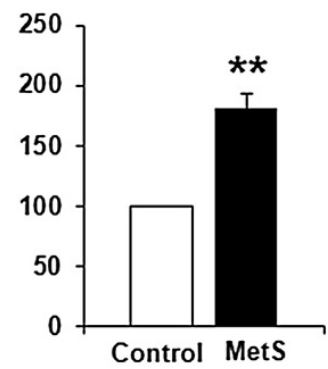

Rho-associated kinase activity (\% related to controls)

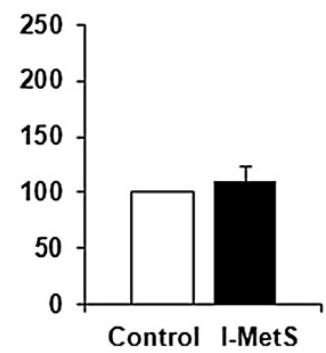

Figure 6 Activation of RhoA/Rho-kinase pathway in mesenteric PVAT. A, Mesenteric PVAT from MetS mice showed increased gene expression of RhoA and Rho-kinases. Rho-kinase activity was also significantly increased, which was not seen in I-MetS mice (B). Data represent the mean \pm SEM from $2-4$ independent experiments, $n=3-4$ mice/group, ${ }^{*} P<0.05$, ${ }^{* *} P<0.01$.

activation [44], contributes to the loss of this protective vascular effect $[23,45]$. In our study, mice with I-MetS did not show signs of dysfunctional PVAT, presenting with neither infiltration by inflammatory cells nor increased expression of inflammatory genes. Loss of the anticontractile effect was only seen in MetS mice and not in the I-MetS group. Activation of the reninangiotensin-aldosterone system $[46,47]$ is involved in diet-induced obesity, since hypertrophied adipocytes can serve as a source of angiotensin II [48]. Although our experiments do not rule out the role of angiotensin II in early stages of disease development, the PVAT had a protective role in vasoconstriction responses in I-MetS mice. This observation is at odds with the potential deleterious effect of angiotensin II.

Adiponectin has been addressed as an important vasodilator effector secreted from PVAT, and Greenstein et al. reported loss of the protective vasodilator effect of PVAT involving adiponectin in obese patients [16]. Moreover, lower levels of adiponectin, in particular HMW adiponectin, have been linked to MetS [49]. We observed decreased HMW adiponectin levels only in serum of MetS mice.

Another aspect related to PVAT addressed in this study was activation of the RhoA/Rho-kinase pathway, a key modulator of vascular smooth muscle contraction [50] and contributor to the pathophysiology of arterial hypertension [51]. Rho-kinase activity was reported to be upregulated in leukocytes from patients with MetS [52] and hypertension [53]. In animal models of hypertension, increased Rho-kinase activity was detected in vascular tissues [54,55]. More recently Hara et al. showed that stretching of adipocytes by accumulated lipid triggers RhoA/Rho-kinase signaling and the subsequent expression of inflammatory genes. Therefore, RhoA/Rho-kinase signaling is implicated in inflammatory changes in adipose tissue in obesity, contributing to and aggravating weight gain and insulin resistance [56]. Thus, it is plausible to hypothesize that signaling originating from PVAT influences vascular contractility. Interestingly, we saw that although PVAT from I-MetS mice was already hypertrophied there was no evidence of Rho-kinase activation; the latter was seen only in MetS mice, suggesting that the augmented vasoconstriction in I-MetS occurred independently of PVATderived RhoA/Rho-kinase signaling.

\section{Conclusion}

In summary, this study identified distinct patterns of microvascular dysfunction in MetS, with augmented 
vasoconstriction present in the initial phase of MetS independent of endothelial dysfunction, insulin resistance, inflammation, and a dysfunctional PVAT, features commonly accepted as modulators of microvascular function. Our findings strongly suggest that, in I-MetS, the augmented vasoconstriction was caused by vascular smooth muscle cell dysfunction. These results shed light on the link between MetS and increased CVD risk. We cannot state the relevance of these results to human MetS. Further research is needed to identify the mechanisms of early microvascular changes and to provide improved preventive strategies aiming to decrease the CVD risk associated with MetS.

\begin{abstract}
Abbreviations
CVD: Cardiovascular diseases; EDTA: Ethylenediaminetetraacetic acid; ELISA: Enzyme-linked immunosorbent assay; GAPDH: Glyceraldehyde 3phosphate dehydrogenase; HFD: High-fat diet; HMW: High molecular weight; HOMA-IR: Homeostasis model assessment-insulin resistance index;

HyD: Hybrid detectors; IL-6: Interleukin-6; I-MetS: Initial metabolic syndrome; MCP-1: Monocyte chemotactic protein-1; MetS: Metabolic syndrome; MOPS: 3-(N-morpholino)propanesulfonic acid; MRI: Magnetic resonance imaging; NO: Nitric oxide; PCR: Polymerase chain reaction; PVAT: Perivascular adipose tissue; ROCK1: Rho-kinase 1; ROCK2: Rho-kinase 2; SDS-PAGE: Sodium dodecyl sulfate polyacrylamide gel electrophoresis; TE: Echo time; TLR4: Tolllike receptor 4; TNF-a: Tumor necrosis factor-a; WT: Wild type.
\end{abstract}

\section{Competing interests}

The authors declare that they have no competing interests.

\section{Authors' contributions}

CA generated data, analyzed the data and wrote the manuscript. CA and MB designed the research and wrote the manuscript. $\mathrm{RM}, \mathrm{IH}$ and $\mathrm{RB}$ generated data. SC, ES, RE, DS, CS, CW, UH, MT contributed to discussions and reviewed the manuscript. CA and MB are the guarantors of this work and, as such, had full access to all the data in the study and takes responsibility for the integrity of the data and the accuracy of the data analysis. All authors read and approved the final manuscript.

\section{Acknowledgements}

We acknowledge the professional technical help received from Alina Schmidt, Sandra Haderer and Marcel Konhäuser.

\section{Funding}

This study is funded by a research grant of the Kommission für Klinische Forschung (KKF) of the Klinikum rechts der Isar der Technischen Universität München. Two-photon laser scanning microscopy experiments were supported by the DFG (INST 409/97-1 and FOR809).

\footnotetext{
Author details

${ }^{1}$ Department of Nephrology, Klinikum rechts der Isar der Technischen Universität München, Ismaninger St. 22, Munich 81675, Germany. ${ }^{2}$ Department of Human Molecular Genetics, Laboratory of High-throughput Technologies, Institute of Molecular Biology and Biotechnology, Faculty of Biology, Adam Mickiewicz University, Poznan, Poland. ${ }^{3}$ Dept of Otorhinolaryngology, Klinikum rechts der Isar der Technischen Universität München, Munich, Germany. ${ }^{4}$ Institute of Radiology, Klinikum rechts der Isar der Technischen Universität München, Munich, Germany. ${ }^{5}$ Institute for Cardiovascular Prevention, Ludwig-Maximilian-Universität, Munich, Germany. ${ }^{6}$ Cardiovascular Research Institute Maastricht (CARIM), Maastricht University, Maastricht, the Netherlands. ${ }^{7}$ German Centre for Cardiovascular Research (DZHK), partner site Munich Heart Alliance, Munich, Germany. Institute for Diabetes and Obesity, Helmholtz Zentrum München, Munich, Germany.
}

Received: 28 January 2014 Accepted: 29 January 2014

Published: 3 February 2014

\section{References}

1. Yusuf S, Hawken S, Ounpuu S, Dans T, Avezum A, Lanas F, McQueen M, Budaj A, Pais P, Varigos J, et al: Effect of potentially modifiable risk factors associated with myocardial infarction in 52 countries (the INTERHEART study): case-control study. Lancet 2004, 364:937-952.

2. Alberti KG, Zimmet P, Shaw J, Group IDFETFC: The metabolic syndrome-a new worldwide definition. Lancet 2005, 366:1059-1062.

3. Grundy SM, Brewer HB Jr, Cleeman JI, Smith SC Jr, Lenfant C, American Heart A, National Heart L, Blood I: Definition of metabolic syndrome: report of the national heart, lung, and blood institute/american heart association conference on scientific issues related to definition. Circulation 2004, 109:433-438.

4. Alexander CM, Landsman PB, Teutsch SM, Haffner SM: NCEP-defined metabolic syndrome, diabetes, and prevalence of coronary heart disease among NHANES III participants age 50 years and older. Diabetes 2003 52:1210-1214.

5. Deboer MD: Obesity, systemic inflammation, and increased risk for cardiovascular disease and diabetes among adolescents: a need for screening tools to target interventions. Nutrition 2013, 29:379-386.

6. Arnlov J, Ingelsson E, Sundstrom J, Lind L: Impact of body mass index and the metabolic syndrome on the risk of cardiovascular disease and death in middle-aged men. Circulation 2010, 121:230-236.

7. Rossi M, Matteucci E, Pesce M, Consani C, Franzoni F, Santoro G, Giampietro O: Peripheral microvascular dysfunction as an independent predictor of atherosclerotic damage in type 1 diabetes patients: a preliminary study. Hemorheol Microcirc 2012, 54:381-391.

8. Levy BI, Ambrosio G, Pries AR, Struijker-Boudier HA: Microcirculation in hypertension: a new target for treatment? Circulation 2001, 104:735-740.

9. Mulvany MJ: Structure and function of small arteries in hypertension. J Hypertens Supp/ 1990, 8:S225-232.

10. Panazzolo DG, Sicuro FL, Clapauch R, Maranhao PA, Bouskela E, KraemerAguiar LG: Obesity, metabolic syndrome, impaired fasting glucose, and microvascular dysfunction: a principal component analysis approach. BMC Cardiovasc Disord 2012, 12:102.

11. Hrnciar J, Avdicova M, Gabor D, Hrnciarova M, Chamulova M, Jakubikova K, Kaliska G, Kikova V, Kovar F, Kreze A Jr, et al: Prevalence of metabolic syndrome, insulin resistance, and microvascular angina pectoris in 500 consecutive patients referred to coronarography. Endocr Regul 2013, 47:33-38.

12. Pirat B, Bozbas H, Simsek V, Yildirir A, Sade LE, Gursoy Y, Altin C, Atar I, Muderrisoglu $\mathrm{H}$ : Impaired coronary flow reserve in patients with metabolic syndrome. Atherosclerosis 2008, 201:112-116.

13. Yudkin JS, Eringa E, Stehouwer CD: "Vasocrine" signalling from perivascular fat: a mechanism linking insulin resistance to vascular disease. Lancet 2005, 365:1817-1820.

14. Muris DM, Houben AJ, Schram MT, Stehouwer CD: Microvascular dysfunction: an emerging pathway in the pathogenesis of obesityrelated insulin resistance. Rev Endocr Metab Disord 2013, 14:29-38.

15. Stapleton PA, Goodwill AG, James ME, Brock RW, Frisbee JC: Hypercholesterolemia and microvascular dysfunction: interventional strategies. J Inflamm (Lond) 2010, 7:54.

16. Greenstein AS, Khavandi K, Withers SB, Sonoyama K, Clancy O, Jeziorska M, Laing I, Yates AP, Pemberton PW, Malik RA, Heagerty AM: Local inflammation and hypoxia abolish the protective anticontractile properties of perivascular fat in obese patients. Circulation 2009, 119:1661-1670.

17. Stapleton PA, James ME, Goodwill AG, Frisbee JC: Obesity and vascular dysfunction. Pathophysiology 2008, 15:79-89.

18. Verlohren S, Dubrovska G, Tsang SY, Essin K, Luft FC, Huang Y, Gollasch M: Visceral periadventitial adipose tissue regulates arterial tone of mesenteric arteries. Hypertension 2004, 44:271-276.

19. Lohn M, Dubrovska G, Lauterbach B, Luft FC, Gollasch M, Sharma AM: Periadventitial fat releases a vascular relaxing factor. FASEB J 2002, 16:1057-1063

20. Schmid PM, Resch M, Steege A, Fredersdorf-Hahn S, Stoelcker B, Birner C, Schach C, Buechler C, Riegger GA, Luchner A, Endemann DH: Globular and full-length adiponectin induce NO-dependent vasodilation in resistance arteries of Zucker lean but not Zucker diabetic fatty rats. Am J Hypertens 2011, 24:270-277.

21. Cao Y, Tao L, Yuan Y, Jiao X, Lau WB, Wang Y, Christopher T, Lopez B, Chan L, Goldstein B, Ma XL: Endothelial dysfunction in adiponectin deficiency and its mechanisms involved. J Mol Cell Cardiol 2009, 46:413-419. 
22. Schmid PM, Resch M, Schach C, Birner C, Riegger GA, Luchner A, Endemann DH: Antidiabetic treatment restores adiponectin serum levels and APPL1 expression, but does not improve adiponectin-induced vasodilation and endothelial dysfunction in Zucker diabetic fatty rats. Cardiovasc Diabetol 2013, 12:46.

23. Owen MK, Witzmann FA, McKenney ML, Lai X, Berwick ZC, Moberly SP, Alloosh M, Sturek M, Tune JD: Perivascular adipose tissue potentiates contraction of coronary vascular smooth muscle: influence of obesity. Circulation 2013, 128:9-18.

24. Oliveira Junior SA, Padovani CR, Rodrigues SA, Silva NR, Martinez PF, Campos DH, Okoshi MP, Okoshi K, Dal-Pai M, Cicogna AC: Extensive impact of saturated fatty acids on metabolic and cardiovascular profile in rats with diet-induced obesity: a canonical analysis. Cardiovasc Diabetol 2013, 12:65

25. Sarkozy M, Zvara A, Gyemant N, Fekete V, Kocsis GF, Pipis J, Szucs G, Csonka C, Puskas LG, Ferdinandy P, Csont T: Metabolic syndrome influences cardiac gene expression pattern at the transcript level in male ZDF rats. Cardiovasc Diabetol 2013, 12:16.

26. Gallou-Kabani C, Vige A, Gross MS, Rabes JP, Boileau C, Larue-Achagiotis C, Tome D, Jais JP, Junien C: C57BL/6J and A/J mice fed a high-fat diet delineate components of metabolic syndrome. Obesity (Silver Spring) 2007, 15:1996-2005.

27. Christensen KL, Mulvany MJ: Location of resistance arteries. J Vasc Res 2001, 38:1-12

28. Christensen KL, Mulvany MJ: Mesenteric arcade arteries contribute substantially to vascular resistance in conscious rats. J Vasc Res 1993, 30:73-79.

29. Fenger-Gron J, Mulvany MJ, Christensen KL: Mesenteric blood pressure profile of conscious, freely moving rats. J Physiol 1995, 488(Pt 3):753-760

30. Matthews DR, Hosker JP, Rudenski AS, Naylor BA, Treacher DF, Turner RC: Homeostasis model assessment: insulin resistance and beta-cell function from fasting plasma glucose and insulin concentrations in man. Diabetologia 1985, 28:412-419.

31. Mather K: Surrogate measures of insulin resistance: of rats, mice, and men. Am J Physiol Endocrinol Metab 2009, 296:E398-399.

32. Megens RT, Reitsma S, Schiffers PH, Hilgers RH, De Mey JG, Slaaf DW, oude Egbrink MG, van Zandvoort MA: Two-photon microscopy of vital murine elastic and muscular arteries. Combined structural and functional imaging with subcellular resolution. J Vasc Res 2007, 44:87-98,

33. Livak KJ, Schmittgen TD: Analysis of relative gene expression data using real-time quantitative PCR and the 2(-Delta Delta $C(T)$ ) Method. Methods 2001, 25:402-408

34. Mulvany MJ, Halpern W: Contractile properties of small arterial resistance vessels in spontaneously hypertensive and normotensive rats. Circ Res 1977, 41:19-26.

35. Zhu W, Cheng KK, Vanhoutte PM, Lam KS, Xu A: Vascular effects of adiponectin: molecular mechanisms and potential therapeutic intervention. Clin Sci (Lond) 2008, 114:361-374.

36. International Diabetes Federation. http://www.idf.org/publications.

37. Jebelovszki E, Kiraly C, Erdei N, Feher A, Pasztor ET, Rutkai I, Forster T, Edes I, Koller A, Bagi Z: High-fat diet-induced obesity leads to increased NO sensitivity of rat coronary arterioles: role of soluble guanylate cyclase activation. Am J Physiol Heart Circ Physiol 2008, 294:H2558-2564.

38. Singer $G$, Granger $D N$ : Inflammatory responses underlying the microvascular dysfunction associated with obesity and insulin resistance. Microcirculation 2007, 14:375-387.

39. Ouwens DM, Sell H, Greulich S, Eckel J: The role of epicardial and perivascular adipose tissue in the pathophysiology of cardiovascular disease. J Cell Mol Med 2010, 14:2223-2234.

40. Ninomiya JK, L'Italien G, Criqui MH, Whyte JL, Gamst A, Chen RS: Association of the metabolic syndrome with history of myocardial infarction and stroke in the third national health and nutrition examination survey. Circulation 2004, 109:42-46.

41. Doyle AE, Fraser JR, Marshall RJ: Reactivity of forearm vessels to vasoconstrictor substances in hypertensive and normotensive subjects. Clin Sci 1959, 18:441-454.

42. Doyle AE, Fraser JR: Vascular reactivity in hypertension. Circ Res 1961, 9:755-761

43. Ritchie RH, Leo CH, Qin C, Stephenson EJ, Bowden MA, Buxton KD, Lessard SJ, Rivas DA, Koch LG, Britton SL, et al: Low intrinsic exercise capacity in rats predisposes to age-dependent cardiac remodeling independent of macrovascular function. Am J Physiol Heart Circ Physiol 2013, 304:H729-739.
44. Withers SB, Agabiti-Rosei C, Livingstone DM, Little MC, Aslam R, Malik RA, Heagerty AM: Macrophage activation is responsible for loss of anticontractile function in inflamed perivascular fat. Arterioscler Thromb Vasc Biol 2011, 31:908-913.

45. Aghamohammadzadeh R, Greenstein AS, Yadav R, Jeziorska M, Hama S, Soltani F, Pemberton PW, Ammori B, Malik RA, Soran H, Heagerty AM: Effects of bariatric surgery on human small artery function: evidence for reduction in perivascular adipocyte inflammation, and the restoration of normal anticontractile activity despite persistent obesity. J Am Coll Cardiol 2013, 62:128-135.

46. Sharma AM: Is there a rationale for angiotensin blockade in the management of obesity hypertension? Hypertension 2004, 44:12-19.

47. Massiera F, Bloch-Faure M, Ceiler D, Murakami K, Fukamizu A, Gasc JM, Quignard-Boulange A, Negrel R, Ailhaud G, Seydoux J, et al: Adipose angiotensinogen is involved in adipose tissue growth and blood pressure regulation. FASEB J 2001, 15:2727-2729.

48. Yiannikouris F, Gupte M, Putnam K, Thatcher S, Charnigo R, Rateri DL, Daugherty A, Cassis LA: Adipocyte deficiency of angiotensinogen prevents obesity-induced hypertension in male mice. Hypertension 2012, 60:1524-1530

49. Hara K, Horikoshi M, Yamauchi T, Yago H, Miyazaki O, Ebinuma H, Imai Y, Nagai R, Kadowaki T: Measurement of the high-molecular weight form of adiponectin in plasma is useful for the prediction of insulin resistance and metabolic syndrome. Diabetes Care 2006, 29:1357-1362.

50. Hilgers RH, Webb RC: Molecular aspects of arterial smooth muscle contraction: focus on Rho. Exp Biol Med (Maywood) 2005, 230:829-835.

51. Wirth A: Rho kinase and hypertension. Biochim Biophys Acta 1802, 2010:1276-1284.

52. Liu PY, Chen JH, Lin $L$, Liao JK: Increased Rho kinase activity in a Taiwanese population with metabolic syndrome. J Am Coll Cardiol 2007, 49:1619-1624

53. Hata T, Soga J, Hidaka T, Idei N, Fujii Y, Fujimura N, Mikami S, Maruhashi T, Kihara Y, Chayama K, et al: Calcium channel blocker and Rho-associated kinase activity in patients with hypertension. J Hypertens 2011, 29:373-379.

54. Seasholtz TM, Zhang T, Morissette MR, Howes AL, Yang AH, Brown JH: Increased expression and activity of RhoA are associated with increased DNA synthesis and reduced p27(Kip1) expression in the vasculature of hypertensive rats. Circ Res 2001, 89:488-495.

55. Moriki N, Ito M, Seko T, Kureishi Y, Okamoto R, Nakakuki T, Kongo M, Isaka N, Kaibuchi K, Nakano T: RhoA activation in vascular smooth muscle cells from stroke-prone spontaneously hypertensive rats. Hypertens Res 2004, 27:263-270.

56. Hara Y, Wakino S, Tanabe Y, Saito M, Tokuyama H, Washida N, Tatematsu S, Yoshioka K, Homma K, Hasegawa K, et al: Rho and Rho-kinase activity in adipocytes contributes to a vicious cycle in obesity that may involve mechanical stretch. Sci Signal 2011, 4:ra3.

doi:10.1186/1475-2840-13-31

Cite this article as: Aoqui et al:: Microvascular dysfunction in the course of metabolic syndrome induced by high-fat diet. Cardiovascular Diabetology 2014 13:31.

\section{Submit your next manuscript to BioMed Central and take full advantage of:}

- Convenient online submission

- Thorough peer review

- No space constraints or color figure charges

- Immediate publication on acceptance

- Inclusion in PubMed, CAS, Scopus and Google Scholar

- Research which is freely available for redistribution 